\title{
Ureter Cancer by AJCC v7 Stage
}

National Cancer Institute

\section{Source}

National Cancer Institute. Ureter Cancer by A/CC v7 Stage. NCI Thesaurus. Code C140378.

A term that refers to the staging of ureter cancer according to the American Joint Committee on Cancer, 7 th edition. 